\title{
KEMAMPUAN MENGGUNAKAN EJAAN BAHASA INDONESIA DALAM TEKS EKSPOSISI PADA PESERTA DIDIK KELAS VIII SMPN 7 BANJARMASIN TAHUN AJARAN 2018/2019
}

\section{THE ABILITY TO USE INDONESIAN SPELLING IN THE EXPOSITION TEXT OF CLASS VIII STUDENTS OF BANJARMASIN 7 JUNIOR HIGH SCHOOL YEAR 2018/2019}

\author{
Riska Febrianty; Zakiah Agus Kusasi; Noor Cahaya \\ Program Studi Pendidikan Bahasa dan Sastra Indonesia \\ FKIP Universitas Lambung Mangkurat \\ riskafebrianty127@gmail.com
}

\begin{abstract}
Abstrak
Penelitian dilaksanakan bertujuan untuk mendeskripsikan penguasaan, penerapan, dan pemakaian Ejaan Bahasa Indonesia dalam teks eksposisi peserta didik kelas VIII SMPN 7 Banjarmasin. Penelitian ini menggunakan metode deskriptif kuantitatif dengan populasi berjumlah 256 orang dan ditetapkan sampel sebesar 63 orang. Besar sampel ini yaitu $25 \%$ dari jumlah populasi. Berdasarkan hasil analisis data, rerata penguasaan EBI kelas VIII adalah 64,9206 yang termasuk dalam kategori "cukup mampu". Rerata penerapan EBI kelas VIII adalah 54,0159 yang termasuk dalam kategori "kurang mampu". Persentase pemakaian EBI pada peserta didik kelas VIII SMPN 7 Banjarmasin, yaitu 30\% "pemakaian huruf", 30\% "penulisan kata", 38\% "pemakaian tanda baca", dan $2 \%$ "penulisan unsur serapan". Persentase kesalahan pemakaian EBI pada peserta didik kelas VIII SMPN 7 Banjarmasin, yaitu 64,2\% kesalahan pemakaian huruf, 14,5\% kesalahan penulisan kata, 20,9\% "kesalahan pemakaian tanda baca", dan 0,4\% "kesalahan penulisan unsur serapan".
\end{abstract}

Kata Kunci: kemampuan, EBI, eksposisi.

\begin{abstract}
This research was conducted aimed at describing mastery, application, and use of Indonesian Spelling in the exposition text of class VIII students of SMP 7 Banjarmasin. This study uses descriptive quantitative method with a population of 256 people, set a sample for this study, which is as many as 63 people. This sample size is $25 \%$ of the population. Based on the results of data analysis, the average mastery of EBI class VIII is 64.9206 which falls into the category of "quite capable". The mean application of EBI class VIII is 54.0159 which falls into the category of "less capable". The percentage of EBI usage is 30\% "letter usage", 30\% "word writing", 38\% "punctuation usage", and 2\% "absorption element writing". EBI usage errors are $64.2 \%$ letter usage errors, $14.5 \%$ word writing errors, $20.9 \%$ punctuation usage errors, and $0.4 \%$ absorption element writing errors.
\end{abstract}

Keywords: ability, EBI, exposition. 


\section{Pendahuluan}

Ejaan adalah aturan mengenai keseluruhan "pemakaian kata", "penulisan huruf", "pemakaian tanda baca", dan "penulisan unsur serapan" yang bertujuan untuk lebih memperjelas suatu makna dalam ujaran maupun bentuk tulisan.

Penelitian ini lebih menekankan pada kemampuan yang dimiliki peserta didik. Selama ini pembelajaran EBI diajarkan hanya sebagai pelajaran tambahan dalam suatu materi padahal EBI sangat penting untuk diajarkan. Buktinya, masih banyak terdapat kesalahan baik itu pemakaian kata dan pemakaian tanda baca.

Kesalahan mengenai pemakaian EBI masih banyak ditemui dalam berbagai macam media masa dan elektronik yang akan berakibat pada kesalahan penggunaan EBI terus-menerus. Hal ini, akan berakibat pada pengetahuan peserta didik dalam menggunakan EBI karena media masa maupun elektronik sangat berperan penting dalam perkembangan pembelajaran. Melalui penelitian ini dapat memberikan pembelajaran atau pengenalan secara bertahap bagaimana menggunakan EBI yang baik, benar, dan tepat agar peserta didik dapat lebih fasih lagi dalam menggunakan Ejaan Bahasa Indonesia.

Berbagai macam penelitian mengenai EBI telah banyak diteliti. Namun, penelitian inipun dibuat untuk mengetahui kemampuan peserta didik dalam menggunakan Ejaan Bahasa Indonesia dalam teks eksposisi. Berdasarkan penguasaan EBI peserta didik, penerapan EBI peserta didik, dan pemakaian EBI kelas VIII. Hal ini, dapat melatih peserta didik dalam menggunakan EBI yang benar, yaitu sesuai dengan "Pedoman Umum Ejaan Bahasa Indonesia". Dengan demikian, untuk ke depannya pembelajaran mengenai EBI lebih ditekankan lagi oleh tenaga pendidik agar peserta didik lebih terasah kemampuannya dalam menggunakan Ejaan Bahasa Indonesia.

\section{Metode Penelitian}

\section{Jenis Penelitian}

Pendekatan pada penelitian ini, yaitu metode deskriptif kuantitatif. Data yang diperoleh berupa gejala tingkat kemampuan menggunakan EBI setelah itu dideskripsikan dan diolah dengan menggunakan "statistik" untuk memperoleh persentase yang dapat digunakan untuk menyimpulkan hasil penelitian.

\section{Waktu dan Tempat}

Peneliti melaksanakan penelitian, di kelas VIII A dan D di SMP Negeri 7 Banjarmasin dilaksanakan secara berskala waktu, sampel kelas A diambil Jumat, 1611-2018 dan kelas D diambil Senin, 19-112018. 


\section{Populasi dan Sampel}

Populasi penelitian yaitu peserta didik kelas VIII tahun pelajaran 2018/2019 yaitu sebanyak 256 orang, dengan perincian jumlah peserta didik di setiap kelas VIII adalah 32 orang. Diketahui populasi, yaitu sebesar 256 orang dan ditetapkan sampel sebanyak 63 orang dengan $25 \%$ dari besarnya populasi.

\section{Teknik Pengumpulan Data}

Pengumpulan data dilakukan dengan teknik tes, yaitu tes kemampuan menggunakan Ejaan Bahasa Indonesia dengan melakukan beberapa jenis tes, (1) tes penguasaan Ejaan Bahasa Indonesia berupa 20 soal pilihan ganda, (2) tes penerapan Ejaan Bahasa Indonesia berupa 10 soal esai, dan (3) tes pemakaian Ejaan Bahasa Indonesia dalam mengarang/menulis eksposisi berdasarkan tema yang disediakan dan berdasarkan Ejaan Bahasa Indonesia yang tepat.

\section{Teknik Analisis Data}

Analisis data yang diperoleh menggunakan analisis statistik deskriptif. Statistik deskriptif digunakan untuk "menghitung skor rerata", "simpangan baku", "varian", "maksimum", “minimum”, “sum”, “range”, "kurtosis", dan "skewness". Skor rerata/(mean) selanjutnya dikategorikan sehingga diperoleh frekuensi persentase.

Data yang telah dikumpul dianalisis melalui langkah-langkah sebagai berikut: (1) mengidentifikasi hasil jawaban dan tulisan peserta didik, (2) menentukan skor tes penguasaan, tes penerapan, dan tes pemakaian Ejaan Bahasa Indonesia dalam teks eksposisi, berdasarkan aspek yang diteliti, (3) penentuan nilai mentah menjadi skor, (4) menentukan nilai rata-rata dari data yang didapatkan menggunakan SPSS, (5) mengkoversikan kemampuan rata-rata berdasarkan penilaian berdasarkan statistik SPSS, (6) menentukan klasifikasi kemampuan dengan menampilkan histogram (pie chart) dari hasil olahan data, dan (7) menyimpulkan hasil analisis data.

\section{Hasil Penelitian}

Penguasaan Ejaan Bahasa Indonesia

Tabel 1 Statistik Penguasaan Ejaan

Bahasa Indonesia Kelas VIII

\begin{tabular}{|l|c|c|c|c|c|}
\hline \multicolumn{6}{|c|}{ Deskripsi Statistik } \\
\hline & $\mathrm{N}$ & Rerata & $\begin{array}{c}\text { Standar } \\
\text { Deviasi }\end{array}$ & $\begin{array}{c}\text { Mini } \\
\text { mum }\end{array}$ & $\begin{array}{c}\text { Maks } \\
\text { imum }\end{array}$ \\
\hline $\begin{array}{l}\text { Peng } \\
\text { uasa } \\
\text { an }\end{array}$ & 63 & $\begin{array}{c}64.920 \\
6\end{array}$ & $\begin{array}{c}9.8575 \\
4\end{array}$ & 40.00 & 80.00 \\
\hline $\begin{array}{l}\text { Vali } \\
\text { d N }\end{array}$ & 63 & & & & \\
\hline
\end{tabular}

Diketahui bahwa 64.9206 "rerata" untuk menentukan nilai rata-rata, 9.85754 
standar deviasi digunakan untuk mengetahui ukuran untuk menentukan sebaran data dalam sampel, minimum (Xmin) sebesar 40,00 dalam menentukan nilai data statistik terkecil, maximum (Xmax) sebanyak $\quad 80,00$ dalam menentukan nilai data statistik tertinggi.

Tabel 2 Persentase Penguasaan Ejaan Bahasa Indonesia Kelas VIII

\begin{tabular}{|c|l|c|c|c|}
\hline \multicolumn{6}{|c|}{ Persentase Penguasaan EBI } \\
\hline \multicolumn{1}{|c|}{} & $\begin{array}{c}\text { Frekue } \\
\text { nsi }\end{array}$ & Persen & $\begin{array}{c}\text { Persen } \\
\text { Valid }\end{array}$ \\
\hline \multirow{5}{*}{$\begin{array}{l}\text { Vali } \\
\text { d }\end{array}$} & $\begin{array}{l}\text { Tidak } \\
\text { Mampu }\end{array}$ & 5 & 7.9 & 7.9 \\
\cline { 2 - 5 } & $\begin{array}{l}\text { Kurang } \\
\text { Mampu }\end{array}$ & 7 & 11.1 & 11.1 \\
\cline { 2 - 5 } & $\begin{array}{l}\text { Cukup } \\
\text { Mampu }\end{array}$ & 19 & 30.2 & 30.2 \\
\cline { 2 - 5 } & Mampu & 29 & 46.0 & 46.0 \\
\cline { 2 - 5 } & $\begin{array}{l}\text { Sangat } \\
\text { Mampu }\end{array}$ & 3 & 4.8 & 4.8 \\
\cline { 2 - 5 } & Total & 63 & 100.0 & 100.0 \\
\hline
\end{tabular}

Bagan 1 Penguasaan Ejaan Bahasa Indonesia

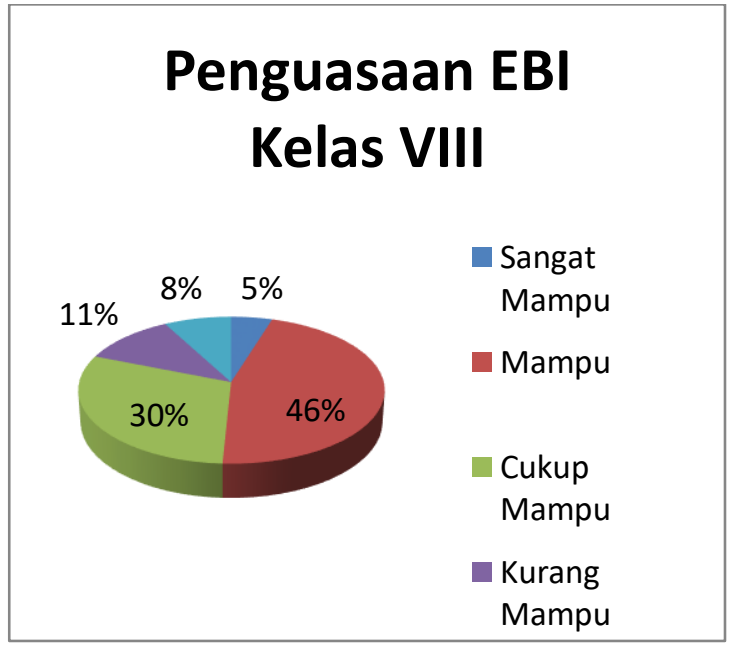

Berdasarkan bagan di atas diketahui bahwa persentase penguasaan EBI kelas VIII A dan kelas VIII D telah ditemukan kumulatif data penguasaan EBI kelas VIII, yaitu 4,8\% peserta didik yang "sangat mampu" dalam penguasaan EBI, 46,0\% peserta didik yang "mampu" dalam penguasaan EBI, $30,2 \%$ peserta didik yang "cukup mampu” dalam penguasaan EBI, $11,1 \%$ peserta didik yang "kurang mатри" dalam penguasaan EBI, dan 7,9\% peserta didik yang "tidak mampu” dalam penguasaan EBI. Dengan demikian, dapat diketahui bahwa rerata penguasaan EBI kelas VIII A dan kelas VIII D adalah 64.9206 yang termasuk dalam kategori “cukup mampu”.

\section{Penerapan Ejaan Bahasa Indonesia}

Tabel 3 Statistik Penerapan Ejaan

Bahasa Indonesia Kelas VIII

\begin{tabular}{|c|c|c|c|c|c|}
\hline \multicolumn{6}{|c|}{ Deskripsi Statistik } \\
\hline & $\mathrm{N}$ & $\begin{array}{c}\text { Rer } \\
\text { ata }\end{array}$ & $\begin{array}{l}\text { Standar } \\
\text { Deviasi }\end{array}$ & $\begin{array}{c}\text { Minim } \\
\text { um }\end{array}$ & $\begin{array}{c}\text { Maksi } \\
\text { mum }\end{array}$ \\
\hline $\begin{array}{l}\text { Pene } \\
\text { rapan }\end{array}$ & 63 & $\begin{array}{r}54 . \\
015 \\
9\end{array}$ & $\begin{array}{r}18.584 \\
15\end{array}$ & 11.00 & 80.00 \\
\hline $\begin{array}{l}\text { Valid } \\
\mathrm{N}\end{array}$ & 63 & & & & \\
\hline \multicolumn{6}{|c|}{ Dapat } \\
\hline \multicolumn{6}{|c|}{$\begin{array}{l}\text { "rerata" untuk menentukan nilai rata-rata, } \\
18.58415 \text { standar deviasi digunakan untuk }\end{array}$} \\
\hline \multicolumn{6}{|c|}{ mengetahui nilai statistik untuk } \\
\hline
\end{tabular}


menentukan nilai data statistik terkecil, maximum (Xmax) sebanyak 80,00 dalam menentukan nilai data statistik tertinggi.

Tabel 4 Persentase Penerapan Ejaan

Bahasa Indonesia Kelas VIII

\begin{tabular}{|c|c|c|c|c|}
\hline \multicolumn{5}{|c|}{$\begin{array}{c}\text { Persentase Ejaan Bahasa Indonesia } \\
\text { Kelas VIII }\end{array}$} \\
\hline & & $\begin{array}{c}\text { Frekuens } \\
\mathrm{i}\end{array}$ & $\begin{array}{c}\text { Perse } \\
n\end{array}$ & $\begin{array}{c}\text { Persen } \\
\text { Valid }\end{array}$ \\
\hline \multirow{6}{*}{$\begin{array}{l}\text { Val } \\
\text { id }\end{array}$} & $\begin{array}{l}\text { Tidak } \\
\text { Mampu }\end{array}$ & 22 & 34.9 & 34.9 \\
\hline & $\begin{array}{l}\text { Kurang } \\
\text { Mampu }\end{array}$ & 12 & 19.0 & 19.0 \\
\hline & $\begin{array}{l}\text { Cukup } \\
\text { Mampu }\end{array}$ & 11 & 17.5 & 17.5 \\
\hline & Mampu & 16 & 25.4 & 25.4 \\
\hline & $\begin{array}{l}\text { Sangat } \\
\text { Mampu }\end{array}$ & 2 & 3.2 & 3.2 \\
\hline & Total & 63 & 100.0 & 100.0 \\
\hline
\end{tabular}

Bagan 2 Penerapan Ejaan Bahasa

Indonesia

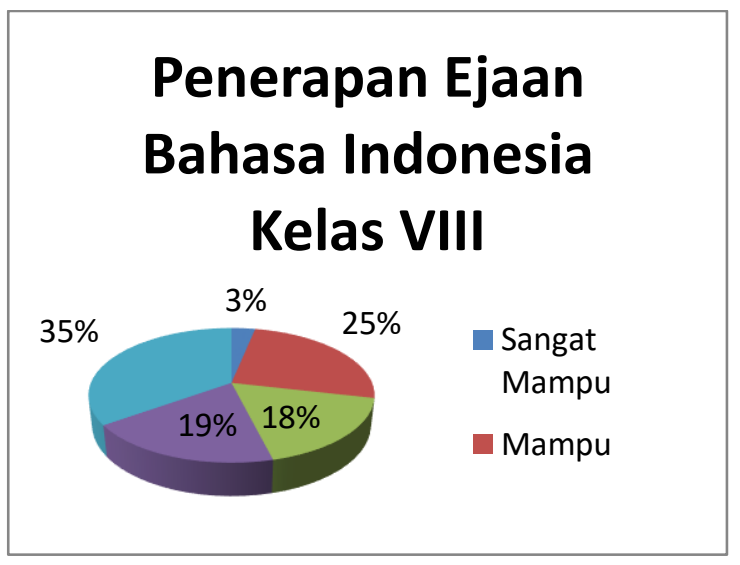

Berdasarkan bagan di atas diketahui bahwa persentase EBI kelas VIII A dan kelas VIII D telah ditemukan kumulatif data penerapan EBI kelas VIII, yaitu 3,2\% peserta didik yang "sangat mampu" dalam penerapan EBI, 25,4\% peserta didik yang “mampu” dalam penerapan EBI, 17,5\% peserta didik yang “cukup mampu” dalam penerapan EBI, 19,0\% peserta didik yang "kurang mampu” dalam penerapan EBI, dan $34,9 \%$ peserta didik yang "tidak mатри" dalam penerapan EBI. Dengan demikian, dapat diketahui bahwa rerata penerapan EBI kelas VIII A dan kelas VIII D adalah 54.0159 yang termasuk dalam kategori "kurang mampu".

\section{Pemakaian Ejaan Bahasa Indonesia}

Persentase pemakaian EBI pada peserta didik kelas VIII sebesar 30\% 'pemakaian huruf', 30\% 'penulisan kata', $38 \%$ 'pemakaian tanda baca', dan $2 \%$ 'penulisan unsur serapan'. Persentase tertinggi pemakaian EBI sebesar $38 \%$ untuk pemakaian tanda baca. Persentase kesalahan pemakaian EBI pada peserta didik kelas VIII sebesar 64,2\% kesalahan pemakaian huruf, 14,5\% kesalahan penulisan kata, 20,9\% "kesalahan pemakaian tanda baca", dan 0,4\% "kesalahan penulisan unsur serapan". Persentase tertinggi "kesalahan pemakaian EBI" sebesar 64,2\% untuk pemakaian huruf.

\section{Pembahasan}

Berdasarkan ciri orang yang mampu terdiri dari: (1) “sanggup”; (2) “cakap”; (3) "kuat"; dan (4) "berusaha dengan diri sendiri”. Ciri tersebut dipaparkan berdasarkan kriteria ketuntasan sekolah 
dengan nilai 7,5 . Ciri orang yang mampu dikaitkan kembali dengan kriteria kemampuan dalam penelitian ini terdapat 5 kriteria, yaitu: (1) "sangat mampu"; (2) "mатри"; (3) “сикuр татрu”; (4) "kurang mampu"; (5) "tidak mampu”.

Kemampuan tersebut dipaparkan menjadi: (1) sangat mampu adalah kemampuan peserta didik dalam menggunakan EBI telah memenuhi keempat ciri orang yang mampu, yaitu sanggup, cakap, kuat, dan berusaha dengan diri sendiri; (2) mampu adalah kemampuan peserta didik dalam menggunakan EBI telah memenuhi ketiga ciri orang yang mampu, yaitu sanggup, cakap, dan berusaha dengan diri sendiri; (3) cukup mampu adalah kemampuan peserta didik dalam menggunakan EBI telah memenuhi dua ciri orang yang mampu, yaitu sanggup dan berusaha dengan diri sendiri; (4) kurang mampu adalah kemampuan peserta didik dalam menggunakan EBI telah memiliki satu ciri orang yang mampu, yaitu berusaha dengan diri sendiri; dan (5) tidak mampu adalah kemampuan peserta didik dalam menggunakan EBI tidak tergolong ke dalam ciri orang yang mampu.

Dapat diketahui ciri orang yang mampu pada penguasaan EBI peserta didik kelas VIII, yaitu 4,8\% peserta didik yang "sangat mampu" rentang nilai, yaitu "80100" sehingga melebihi kriteria ketuntasan sekolah, yaitu 7,5 dan memenuhi keempat ciri orang yang mampu, 46,0\% peserta didik yang "mampu” dengan rentang nilai 70-79 sehingga melebihi dan tidak melebihi kriteria ketuntasan sekolah, yaitu 7,5 dan memenuhi ketiga ciri orang yang mampu, 30,2\% peserta didik yang “cukup татри" dengan rentang nilai 60-69 sehingga tidak melebihi kriteria ketuntasan sekolah, yaitu 7,5 dan memenuhi dua ciri orang yang mampu, $11,1 \%$ peserta didik yang "kurang mampu” dengan rentang nilai 50-59 sehingga tidak melebihi kriteria ketuntasan sekolah, yaitu 7,5 dan memenuhi satu ciri orang yang mampu, dan $7,9 \%$ peserta didik yang "tidak татри" dengan rentang nilai 0-49 sehingga tiak melebihi kriteria ketuntasan sekolah, yaitu 7,5 dan tidak memenuhi ciri orang yang mampu.Dapat diketahui bahwa rerata penguasaan EBI kelas VIII adalah 64.9206 yang termasuk dalam kategori "cukup mampu" dengan memenuhi dua ciri orang yang mampu, yaitu sanggup dan berusaha dengan diri sendiri.

Dapat diketahui ciri orang yang mampu pada penerapan EBI peserta didik kelas VIII, yaitu 3,2\% peserta didik yang "sangat mampu" rentang nilai, yaitu "80100" sehingga melebihi kriteria ketuntasan sekolah, yaitu 7,5 dan memenuhi keempat ciri orang yang mampu, $25,4 \%$ peserta didik yang "mampu” dengan rentang nilai 70-79 sehingga melebihi dan tidak 
melebihi kriteria ketuntasan sekolah, yaitu 7,5 dan memenuhi ketiga ciri orang yang mampu, 17,5\% peserta didik yang "cukup татри" dengan rentang nilai 60-69 sehingga tidak melebihi kriteria ketuntasan sekolah, yaitu 7,5 dan memenuhi dua ciri orang yang mampu, 19,0\% peserta didik yang "kurang maтрu" dengan rentang nilai 50-59 sehingga tidak melebihi kriteria ketuntasan sekolah, yaitu 7,5 dan memenuhi satu ciri orang yang mampu, dan $34,9 \%$ peserta didik yang "tidak татри" dengan rentang nilai 0-49 sehingga tiak melebihi kriteria ketuntasan sekolah, yaitu 7,5 dan tidak memenuhi ciri orang yang mampu.Dapat diketahui bahwa rerata penerapan EBI kelas VIII adalah 54.0159 yang termasuk dalam kategori "kurang mampu" dengan memenuhi satu ciri orang yang mampu, yaitu berusaha dengan diri sendiri.

Berdasarkan dari hasil analisis data mengenai persentase penguasaan EBI kelas VIII SMPN 7 Banjarmasin telah ditemukan kumulatif data penguasaan EBI kelas VIII, yaitu 7,9\% peserta didik yang "tidak mampu" dalam penguasaan EBI, hal ini juga memiliki persamaan dengan Musalfiah (2014) kemampuan penggunaan huruf kapital pada kulifikasi kurang sekali dengan rata-rata $35 \%$. Walaupun hasil penelitian ini menggunakan aspek keseluruhan EBI, sedangkan Musalfiah (2014) menggunakan aspek pemakaian

huruf saja. Persentase penguasaan EBI $11,1 \%$ peserta didik yang "kurang mampu” dalam penguasaan EBI, 30,2\% peserta didik yang “cukup mampu” dalam penguasaan EBI, 46,0\% peserta didik yang "mampu” dalam penguasaan EBI, dan $4,8 \%$ peserta didik yang "sangat mampu" dalam penguasaan EBI.

\section{Simpulan}

Berdasarkan hasil dan pembahasan dapat disimpulkan rerata penguasaan EBI kelas VIII adalah 64.9206 yang termasuk dalam kategori "cukup mampu”. Rerata penerapan EBI kelas VIII adalah 54.0159 yang termasuk dalam kategori "kurang mampu". Persentase pemakaian EBI pada peserta didik kelas VIII sebesar 30\% “pemakaian huruf", 30\% "penulisan kata", $38 \%$ "pemakaian tanda baca", dan $2 \%$ "penulisan unsur serapan". Persentase tertinggi pemakaian EBI sebesar $38 \%$ untuk pemakaian tanda baca. Persentase kesalahan pemakaian EBI pada peserta didik kelas VIII sebesar $64,2 \%$ kesalahan pemakaian huruf, $14,5 \%$ kesalahan penulisan kata, 20,9\% kesalahan "pemakaian tanda baca", dan 0,4\% kesalahan "penulisan unsur serapan". Persentase tertinggi kesalahan pemakaian EBI sebesar 64,2\% untuk pemakaian huruf.

\section{Saran}


Berhubungan dengan hasil penelitian yang diperoleh, peneliti memaparkan saran-saran berikut ini.

1) Bagi peserta didik, dengan adanya penelitian mengenai EBI agar dapat melatih berbagai kemampuan mengenai EBI dan diharapkan dapat lebih mempelajari dan menerapkan EBI baik itu dalam karya tulis lainnya.

2) Bagi tenaga pendidik dengan adanya penelitian ini dapat melakukan pembinaan

\section{Daftar Pustaka}

Arifin, E. Zaenal \& Tasai, S. Amran. 2008.

"Cermat Berbahasa Indonesia". Jakarta: Akademia Pressindo.

Arikunto, Suharsimi. 2002. Prosedur Penelitian Suatu Pendekatan Praktis. Jakarta: PT. Rineka Cipta.

Chaer, Abdul. 1993. "Pembakuan Bahasa Indonesia”. Jakarta: Rineka Cipta.

Eneste, Pamusuk. 2017. Buku Pintar Penyuntingan Naskah: Edisi Ketiga. Jakarta: PT Gramedia Pustaka Utama.

Karyati, Zetty. 2016. "Antara EYD dan PUEBI: Suatu Analisis Komparatif" dalam jurnal SAP Vol. 1 No. 2. Publikasi daring. (diakses 18 Maret 2018)

Keraf, Gorys. 1981. Eksposisi dan Deskripsi. Jakarta: Nusa Indah.

Kep. Mendikbud. 1998. Ejaan yang Disempurnakan (Kep. Mendikbud No. 0543a Th. 1087). Jakarta: Bumi Aksara.

Kosasih. E. 2016. Bahasa Indonesia Kelas VIII Edisi Revisi 2017. Jakarta: mengenai kemampuan berbahasa pada peserta didik dengan membentuk kelompok belajar secara rutin yang membahas tentang EBI dan kemampuan berbahasa lainnya.

3) Bagi peneliti yang ingin meneliti mengenai kemampuan menggunakan EBI selanjutnya, sebaiknya perlu dilanjutkan aspek kemampuan berbahasa lainnya, baik penggunaan kata maupun kalimat.

Kementerian Pendidikan dan Kebudayaan.

Mahsun. 2014. Teks Pembelajaran Bahasa Indonesia Kurikulum 2013. Jakarta: Rajawali Pers.

Martin, Mustakim \& Adriana, Martha Lena. 1995. Pemakaian Bahasa Indonesia Ragam Tulis Di Lingkungan Perguruan Tinggi. Jakarta: Departemen Pendidikan dan Kebudayaan.

Moenta, Andi Pangerang. 2009. "Pedoman Umum Ejaan Bahasa Indonesia Yang Disempurnakan" dalam PUEBI daring. (diakses 18 Maret 2018)

Musalfiah, Annajmi. 2014. "Kemampuan Penggunaan Ejaan Yang Disempurnakan Peserta didik Kelas VIII SMPN 20 Padang dalam Menulis Surat Dinas" dalam e-jurnal Ilmiah. Publikasi daring. (diakses 18 Maret 2018)

Nurgiyantoro, Burhan. 1988. Penilaian dalam Pengajaran Bahasa dan Sastra. Yogyakarta: BPFE IKIP Yogyakarta. 
Nurmawati, dkk. 2012. "Peningkatan KemampuanMenggunakan Tanda Baca Titik, Koma, dan Titik Dua dalam Kalimat dengan Menggunakan Metode Latihan Peserta didik Kelas IV SDN Atananga Kec. Bumi Raya Kab. Morowali" dalam jurnal Kreatif Tadulako Online Vol. 3 No. 1 ISSN 2354-614X. Publikasi daring. (diakses 18 Maret 2018)

Pamungkas. 1972. Pedoman Umum Ejaan Bahasa Indonesia Yang Disempurnakan. Surabaya: Giri Surya.

Purwanto, Ngalim (2006). Psikologi Pendidikan. Bandung: PT Remaja Rosdakarya.

Ridodo, Moli, dkk. 2015. "Pembelajaran Menulis Teks Eksposisi Peserta didik Kelas X Sma Negeri 3 Bandar Lampung" dalam jurnal Kata (Bahasa, Sastra, dan Pembelajarannya). Publikasi daring. (diakses 8 April 2018)

Sari, Lisda dkk. 2013. "Penggunaan Bahasa Indonesia Ragam Tulis di Ruang Publik SMA Negeri Bandar Lampung" dalam jurnal Kata (Bahasa, Sastra, dan
Pembelajarannya). Publikasi daring. (diakses 18 Maret 2018)

Saukah, Ali dan Imam Agus Basuki, dkk. 2017. Pedoman Penulisan Karya Ilmiah: Tugas Akhir, Skripsi, Tesis, Disertasi, Artikel, Makalah dan Laporan Penelitian. Edisi Revisi. Malang: Universitas Negeri Malang.

Suartika, I Putu. 2013. "Kemampuan Peserta didik Menerapkan Ejaan dalam Penulisan Karangan Argumentasi di Kelas X SMA Laboratorium Undiksha Singaraja" dalam Artikel Ilmiah. Publikasi daring. (diakses 18 Maret 2018)

Sudjiono, Anas. (2008). Pengantar Statistik Pendidikan. Jakarta: PT Gramedia.

Sugihastuti. 2000. Bahasa Laporan Penelitian. Yogyakarta: Pustaka Pelajar.

Tim Pengembangan Pedoman Bahasa Indonesia. 2016. Pedoman Umum Ejaan Bahasa Indonesia: Edisi Keempat. Jakarta: Badan Pengembangan dan Pembinaan Bahasa Kementerian Pendidikan dan Kebudayaan. 